\title{
Data Visualization: do impresso ao digital para uma comunicação clara e efetiva dos dados do Governo Federal
}

\author{
Data Visualization: from print to digital for clear and effective communication of \\ Federal Government data
}

\begin{abstract}
BARROS, Viviane; Mestranda em Design da linha de pesquisa em Design de Informação e Interação do Programa de Pós-graduação da Universidade de Brasília.

vivianebarrosnobrega@gmail.com
\end{abstract}

MATSUNAGA, Célia; Professora Doutora da Faculdade de Comunicação e do Programa de Pósgraduação em Design da Universidade de Brasília.

celiamatsunaga@unb.br

\section{Resumo}

A forma como a informação tem sido disponibilizada e transmitida, assim como o design de informação e interação, vem se adaptando às novas tecnologias. Mudanças ocasionadas pelas tecnologias digitais de tempo real das revolucionou a informação na forma de acesso, reprodução e disseminação. Interfaces digitais mudam a maneira como a sociedade consome dados. Soluções gráfico-visuais de data visualization vem sendo aplicadas com o objetivo de tornar clara e eficiente a compreensão de dados técnicos e econômicos de transparência do Governo Federal. A comprovação da efetividade comunicacional do tratamento gráfico-visual do designer de informação e interação é algo que necessita de comprovação acadêmica. Por meio de pesquisa qualitativa com procedimento histórico, observacional e de análise de métricas, busca-se a compreensão da efetividade comunicacional de dados de transparência do governo do Brasil no portal do Tesouro Transparente do Tesouro Nacional. A pesquisa encontra-se em fase de definição do foco a ser analisado.

Palavras Chave: tecnologias digitais; design; informação; visualização de dados.

\begin{abstract}
The way information has been made available and transmitted, as well as information design and interaction, has adapted to new technologies. Changes brought by digital technologies in real time have revolutionized information in the form of availability, reproduction and dissemination. Digital interfaces change the way society consumes data. Graphic-visual data visualization solutions have been applied with the objective of making clear and efficient understanding of technical and economic transparency data of the Federal Government. The evidence of the effectiveness communication of the designer's graphic-visual treatment of information and interaction is something that requires academic verification. Through qualitative research with historical procedures, observational and metric analysis, the research tries to understand the effectiveness of the transparency data of the Brazilian government in the Transparent Treasury portal of the National Treasury. The research is in the defining phase of focus to be analyzed.
\end{abstract}

Keywords: digital technologies; to draw; training; data visualization. 


\title{
1 Introdução
}

$\mathrm{Na}$ atualidade, as formas como as pessoas se comunicam e como as informações são compartilhadas vêm se transformando conforme as TICs (Tecnologias da Informação e Comunicação) avançam tecnologicamente. Essas tecnologias são aliadas nas facilidades e praticidades da vida contemporânea. Como afirma Pierre Lévy (1993), "são dispositivos de comunicação que mudam e se adaptam às suas épocas". Dados técnicos do governo brasileiro que - antes eram publicados na forma de relatório impresso, distribuídos fisicamente aos leitores, público específico, sociedade em geral, hoje, podem ser digitais, interativos, mais acessíveis e em tempo real. São mudanças paradigmáticas que transformaram de forma definitiva os processos comunicacionais e que, consequentemente, mudaram a maneira como as pessoas consomem, compreendem e interagem com essas informações. Por meio de mídias digitais, comunicar tem deixado de ser uma ação passiva e vem se tornado, cada vez mais, uma experiência digital interativa.

Para Logan, existe uma dimensão neurofisiológica comparativamente entre a leitura de um texto em papel versus uma leitura em tela, uma vez que os dois hemisférios cerebrais processam a informação de forma diferente. O texto requer uma leitura cautelosa e atenta e, por isso, seu formato de acesso é extremamente importante.

\begin{abstract}
O hemisfério esquerdo do cérebro está envolvido na produção analítica e na interpretação tanto da linguagem falada quanto da escrita. O hemisfério direito do cérebro, por outro lado, está envolvido no processo sintético da percepção espacial e musical. A leitura de um texto impresso em papel é estritamente um processo do lado esquerdo. A leitura de um texto em tela, não importa quão boa seja a resolução, envolve processos tanto do lado esquerdo quanto do lado direito do cérebro. (LOGAN, 2012, p.219).
\end{abstract}

Com a inserção cada vez maior da tecnologia digital no dia a dia da sociedade, as mídias de comunicação impressa vêm passando por diversas transformações em relação à forma como um conteúdo é armazenado, distribuído e compartilhado. As informações que antes eram consumidas na forma de um produto físico, hoje podem ser obtidas nas mais diversas plataformas digitais como sites ou aplicativos. Surgiram novas relações entre usuários e dispositivos digitais, além de maior interação entre pessoas nas mídias sociais. É um cenário completamente modificado, no qual todos são produtores, consumidores, disseminadores e debatedores de conteúdos informacionais, principalmente por meio de perfis em mídias sociais. E este movimento na rede não somente proporciona diálogos entre pessoas, como deixa vestígios e rastros por onde elas navegaram.

Diariamente surgem inovações na forma como as interações ocorrem, comumente mediadas por algum dispositivo de tecnologia digital e, em sua maioria, ubíquas. Conforme última pesquisa de Nielsen, no Mobile Report ${ }^{1}$, do Nielsen IBOBE, de janeiro de $2015,{ }^{2} 36 \%$ dos usuários de Internet no Brasil fazem o acesso pelo smartphone, percentual que provavelmente neste ano de 2018 já aumentou consideravelmente. Desta maneira, quanto maior a experiência personalizada, maior será a relação de intimidade entre o leitor e o conteúdo. (HORIE;

\footnotetext{
${ }^{1}$ Brasileiros com internet no smartphone já são mais de 70 milhões.

${ }^{2}$ Smartphone é o dispositivo mais usado para acessar a internet. The Nilesen Company. Mobile Report, Nielsen IBOBE.
} 
PLUVINAGE, 2011, P.16). A tecnologia digital permite uma nova forma de consumir, lidar, pensar e armazenar conhecimento.

Quando direcionamos esta comunicação para informações gráfico-visuais de dados econômicos de governo, conhecer o perfil do consumidor por meio de ferramentas de BI (Business Intelligence) é uma etapa essencial para se adquirir informações do usuário e obter uma comunicação de sucesso. Nesse aspecto, o papel da área de conhecimento do design é bastante enriquecedor na busca por soluções empáticas, com foco no usuário. Conhecer os comportamentos e angústias do usuário é fundamental para uma melhor compreensão da problemática do estudo.

A presente pesquisa procurar compreender a real assimilação do conteúdo, por parte dos stakeholders de dados técnicos de governo. Seu foco se concentra nos dados do governo brasileiro disponibilizados pelo portal de dados abertos da Secretaria do Tesouro Nacional, o Tesouro Transparente ${ }^{3}$.

A leitura de um relatório com dados gráficos, catalográficos, infográficos procura transmitir uma mensagem de forma clara, direta e visual. A popularização de artefatos tecnológicos aliada ao acesso à Internet contribuiu para uma maior produção e obtenção da informação. Desta forma, a pesquisa procura comprovar a relação de relevância do design de informação e interação em um processo comunicacional efetivo e de sucesso entre dados técnicos do governo e sociedade.

Será que existe uma comunicação efetiva, entre governo e sociedade, quando se trata de divulgar dados econômicos bastante técnicos do governo brasileiro? Essa informação é clara e compreensível pela sociedade? A discussão dessa pesquisa baseia-se na relevância do design de informação e interação como recurso técnico de visualização de dados (data visualization), para uma comunicação clara e efetiva dessa informação.

\section{Metodologia}

Esta é uma pesquisa qualitativa que utiliza gráficos e dados visuais (visualização de dados) do Governo Federal - disponíveis no portal do Tesouro Nacional, como estudo de caso para análise de sua efetividade enquanto gestores de informações de utilidade pública à população brasileira. A pesquisa vem sendo desenvolvida em três diferentes fases. A primeira relacionada à pesquisa histórica, observacional e comparativa dos dados do Tesouro Nacional. A segunda fase foca a participação direta na tomada de decisões que envolvem o desenvolvimento de design de informação, interfaces gráficas, interações e estudos de visualização de dados como designer em um relatório ainda em fase de definição. A terceira fase será a análise de métricas da ferramenta de analitics do PIWIK e a análise de métricas de repercussão sob a forma de engajamento e compartilhamento nas redes sociais do órgão.

Primeira fase - A pesquisa histórica, observacional e comparativa está sendo aplicada como forma de compreender o percurso da transparência de dados disponíveis no portal do Tesouro Transparente. A partir da escolha de um relatório específico, o projeto se propõe a

\footnotetext{
${ }^{3}$ O portal do Tesouro Transparente é um site que faz parte da Secretaria do Tesouro Nacional/Ministério da Fazenda. A proposta deste portal é apresentar e disponibilizar dados de governo de forma mais fácil e interativa. $\mathrm{O}$ site conta com dados abertos, painéis de dados. Os painéis possibilitam cruzamento de dados de forma intuitiva sem a necessidade de instalação de aplicativos.
} 
aprofundar na relação de sua tecnicidade histórica e a forma pela qual foi construída a relação de transmissão dessas informações técnicas à sociedade ao longo dos anos. A discussão busca verificar se essas relações se deram com clareza, objetividade e se cumpriram o papel de comunicar de forma clara e efetiva.

Segunda Fase - A metodologia propõe uma abordagem centrada na experiência do usuário - User Experience (UX), e na interação homem-computador das informações gráfico-visuais, além dos requisitos da relação Human Computer Interaction $(\mathrm{HCl})$ para uma melhor validação da pesquisa. A proposta é utilizar testes com grupos focais técnicos e identificar suas experiências visuais com os dados de governo. Para Bonsiepe, os designers poderiam intervir exatamente nesse ponto, pois dominam os meios para reduzir a complexidade cognitiva, contribuir para a apresentação da informação de forma útil, desenvolvendo uma interface adequada entre a informação e o usuário/leitor. (BONSIEPE, 2011. P.89). Bonsiepe acrescenta que acha adequado o uso do termo designer de informação, cujo objetivo consiste em fomentar o metabolismo cognitivo, vale dizer, facilitar a assimilação de informação. (BONSIEPE, 2011. P.89). O designer assume a tarefa cognitiva de mapear esses dados para a construção de uma interface para fomentar a compreensão interativa. (BONSIEPE, 2011. P.90).

Terceira fase - O uso da ferramenta institucional de análise de dados PIWIK, semelhante ao Google Analitics. Instrumento de análise de dados usado institucionalmente para analisar com detalhes o acesso a sites e sistemas do órgão.

A outra forma será a análise histórica por meio de repercussão das métricas das redes sociais do órgão em forma de engajamento e compartilhamento. As redes sociais analisadas serão o perfil do Facebook “/TesouroNacional” e o perfil do Twitter “@_Tesouro”.

A proposta de análise por meio das métricas destes dois instrumentos - PIWIK e redes sociais, tem como objetivo confrontar o aumento do acesso e engajamento do conteúdo de transparência do Tesouro Nacional como possível resposta de uma melhor comunicação gráficovisual dos dados do governo.

Após estudos históricos, produção de dados visuais e o estudo de casos, poderá ser comprovado (ou não) o grau de transparência, clareza, consistência e eficiência da comunicação do Governo Federal por meio do tratamento gráfico-visual da visualização de dados e da informação pelo designer de informação. O estudo propõe um avanço tecnológico informacional de uma leitura impressa passando para um produto digital - o que teria possibilitado melhor compreensão da informação, "popularizando" o acesso e a compreensão de dados por meio de uma linguagem visual mais didática e intuitiva.

\section{O Impresso}

O dispositivo de conteúdo impresso é uma plataforma de disseminação de conhecimento que vem se transformando de forma permanente e intensa nos últimos 5 mil anos. Oriundo do códice, página de texto escrita com tinta e pergaminho, papiro ou papel (LOGAN. 2012. P.216), inventado pelos romanos no século I da era cristã, o impresso que hoje conhecemos é um avanço do livro do papiro.

O conceito de livro, então, incorpora as seguintes formas anteriores: tábuas de argila, a escrita egípcia em paredes, estelas babilônicas, rolos escritos à mão com tinta sobre pergaminho, como o Torá (os cinco primeiros livros da Bíblia), usados em serviços religiosos judeus, e livros códice escrito à mão com tinta sobre papiro, pergaminho e 
posteriormente papel. O livro moderno surge com a imprensa, que a princípio é uma versão impressa do livro manuscrito. (LOGAN. 2012).

O produto físico tem vantagens e desvantagens. É um objeto que propicia experiências sensoriais como toque, cheiro e reflexo do papel; também não possui luz interna e a inconveniência de ter a leitura interrompida pelo fim da bateria. Ele está sempre disponível à leitura. Para buscar uma informação em seu conteúdo, utiliza-se o glossário e marcam-se as páginas desejadas com etiquetas adesivas ou marcadores de páginas. É um objeto que tem como principal característica ser estático, imóvel e, não interativo. É durável quando bem conservado pois é feito comumente de material delicado.

\section{O digital}

Um dispositivo de conteúdo digital também tem seus prós e contras. Ele é portátil, porém ainda há um número restrito de volumes publicados. Não precisa de espaço físico para ser armazenado, somente de espaço digital - o que também envolve custos. Costuma ter um preço menor em relação ao livro físico. É possível comprar um título online e obtê-lo imediatamente após a compra. Possui recursos como interatividade, hipertextualidade navegável, busca e acessibilidade. É um produto fisicamente durável, facilmente atualizado, com obsolescência programada e facilmente adquirido em vários idiomas. O livro com recursos digitais permite pesquisa, navegação rápida, hipertextualidade, disponibilidade sob demanda, convergência de informações, glossário e elementos interativos (infográficos navegáveis, vídeos, áudios, geolocalização). O livro digital oferece conveniências e serviços que não existiam quando havia somente o livro impresso. O livro digital ou mídias de disponibilização de informação digital e online são produtos com atualização constante e imediata.

\subsection{A interação}

A relação de interação entre homem e artefatos tecnológicos, mais conhecida como Human Computer Interaction $(\mathrm{HCl})$, tem como objetivo proporcionar, por meio dos seus usos, atribuições e avaliações, conforto e praticidade a produtos de design, além de buscar uma comunicação eficaz e fluida. À medida que o livro migra para o ambiente digital, ele absorve funcionalidades complexas desse meio e supera algumas deficiências de usabilidade frente ao formato físico.

Conforme o suporte de conteúdo muda, as relações de interação entre o homem e estes dispositivos tecnológicos também geram novas leituras e formas de assimilação. "As transformações da tecnologia têm o caráter da evolução orgânica porque todas as tecnologias são extensões do nosso ser físico." (MCLUHAN, 2001). Lupton e Miller comparam a escrita como extensão do corpo, como membro artificial ou uma lente de contato. "Como uma cadeira que sustenta o esqueleto humano a escrita (...) é permanente ao invés de efêmera, capaz de se movimentar no espaço e no tempo, e permanecer legível mesmo na ausência do seu autor" (LUPTON; MILLER, 2011, p.50). O avanço da tecnologia desconstrói a forma como o objeto impresso é linearmente lido, fazendo a escrita se movimentar pelo espaço e tempo por meio de hipertextos.

Hoje em dia o termo "desconstrução" é usado eventualmente para rotular qualquer obra de arte que favoreça a complexidade em detrimento da simplicidade e dramatize as possibilidades formais de produção digital. (LUPTON; MILLER. P.10. 2011). 


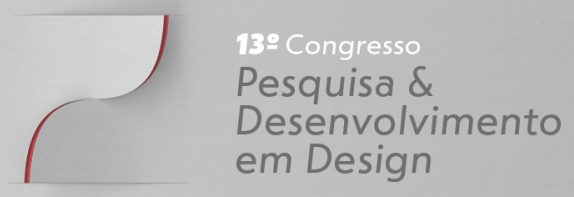

Artigo Completo

A leitura em forma de hipertexto com possibilidades interativas, hipertextuais, multimidiáticas e multissensoriais permite ao leitor uma experiência mais participativa. $\mathrm{O}$ desafio do designer de informação e interação ao trabalhar com esse tipo de produto é oferecer ao usuário final uma forma funcional, agradável e intuitiva de experiência ao interagir com a informação em tempo real.

A pesquisa entre o homem e a assimilação de conteúdos interativos em dispositivos tecnológicos, que geram visualização de dados dentro do Governo Federal, é um estudo recente. A popularização do acesso a dados se expandiu por volta dos anos 2000 (SILVA. STABILE. 2016), com o surgimento de ferramentas de análise de base de dados e a adoção de políticas públicas de acesso à informação. O uso de recursos gráfico-visuais vem se estabelecendo como a melhor forma de comunicar informações complexas.

\subsection{Infografia}

A infografia é um recurso gráfico visual que amplia as possibilidades de absorção de conhecimento de uma informação. A palavra infografia tem origem na união dos termos: info(contração de informação) somado à -grafia (representação escrita de uma palavra). Ou seja, a infografia é uma representação gráfico-visual de elementos que poderiam ser discorridos em um texto. Edward R. Tufte cita em seu livro Envisioning Information (1998) a complexidade do mundo das informações:

O mundo é complexo, dinâmico e multidimensional. O papel é estático e chapado. Como nós podemos representar esta riqueza visual do mundo como a experiência e as medidas em uma superfície chapada? (TUFTE, 1998, p. 9. Tradução da autora).

Os primeiros registros infográficos conhecidos datam dos anos de 1700. A infografia busca explanar, na forma de uma narrativa gráfico-visual, as informações complexas. Para Vassão (2010), o complexo é aquilo que está além da nossa compreensão, por isso o design é essencial para facilitar este diálogo tecnológico. Abaixo temos um exemplo de infografia digital e animada de dados do Tesouro Nacional. A ordem da animação segue a leitura das telas.

Figura 1 - Infografia de dados - Relatório Quadrimestral de Garantias
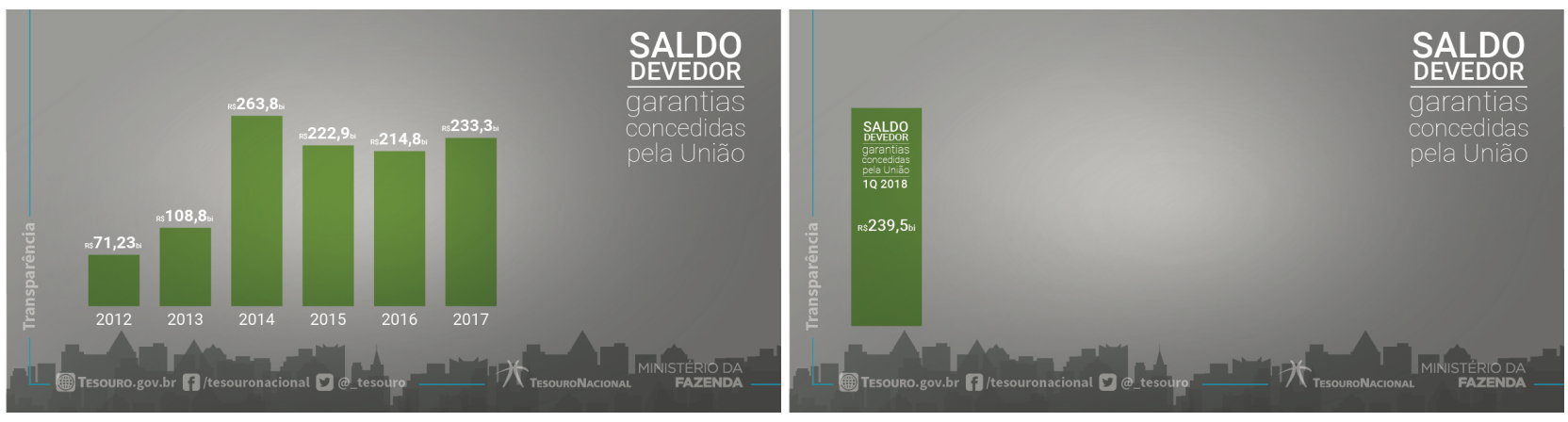

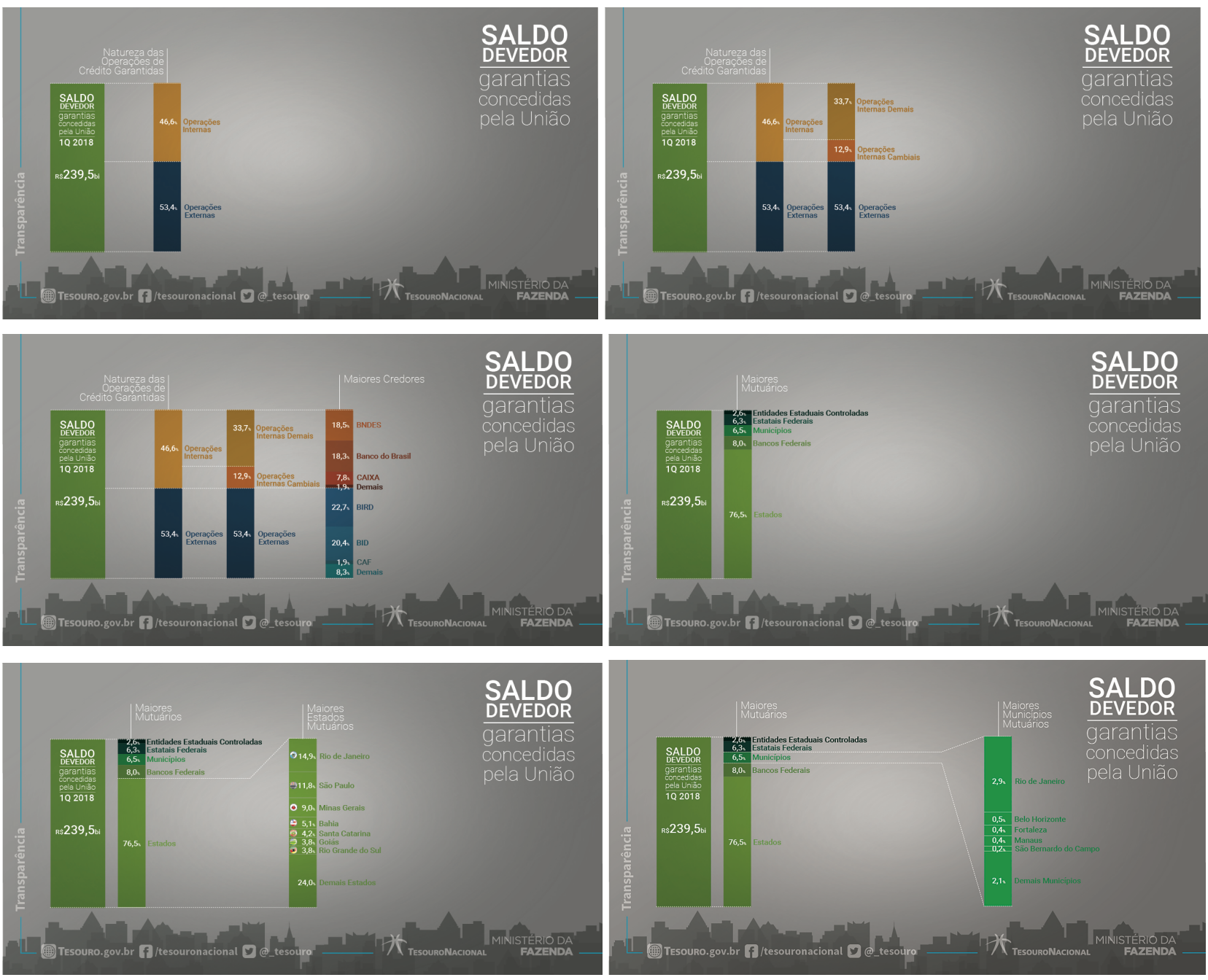

Fonte: Facebook do Tesouro Nacional (@TesouroNacional)

(https://pt-br.facebook.com/tesouronacional/)

\section{Dados econômicos do Governo Federal}

Ao ingressar na área econômica do Governo Federal como analista de programação visual (2009), o desafio era criar melhores visualizações de dados econômicos - bastante técnicos aos olhos leigos da população. A proposta era torna-los compreensíveis, claros e didáticos a todos, independentemente do conhecimento técnico de quem buscava a informação. Naquele período, o trabalho de design no Governo Federal ainda era bastante incipiente. Não se conhecia o valoroso conhecimento técnico do design de informação agregado às ações das instituições públicas, muito menos seu valor estético visual.

Passados três anos, já era possível notar mudanças no comportamento de gestores públicos, não somente em relação à forma como a informação é gerenciada, como também ao entendimento da importância de sua apresentação somadas aos recursos de interação. Em 2012, publicações interativas foram criadas resultantes de uma pós-graduação Latu Sensu em Design de Interação. Com essas inovações, no gabinete do Ministro da Fazenda, as publicações aos poucos foram se tornando cada vez mais digitais, com importantes recursos de interatividade na sua construção. 
Em 2017 - já atuando no Tesouro Nacional, houve maior abertura na pesquisa sobre visualização de dados de Governo Federal. No início do mesmo ano, o portal do Tesouro Transparente (TT) passou por uma grande transformação em seu conceito. Tornou-se um portal de dados abertos mais estruturado, com painéis de visualizações que objetivam facilitar a interação e a compreensão desses dados. O projeto do TT encontra-se no momento em uma terceira fase, com estudos de inovações visuais e tecnológicas e busca de soluções empáticas a aproximação e compreensão de dados de governo pela sociedade.

Abaixo, alguns exemplos ilustram interfaces do Tesouro Transparente antes e depois de 2017 com a implementação de visualização de dados.

Figura 2 - Página inicial do site do Tesouro Transparente antes de 2017

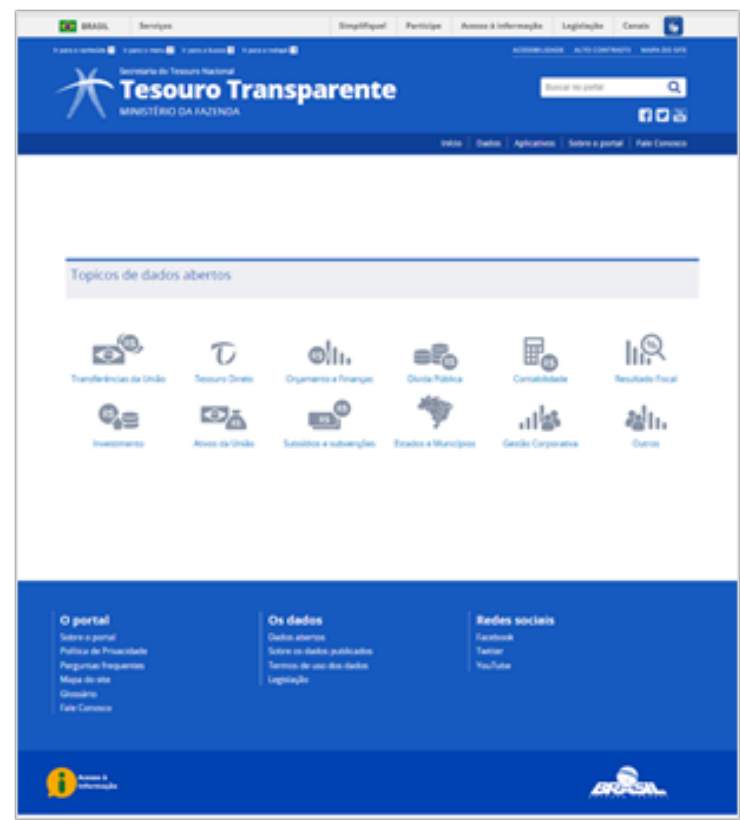

Fonte: Portal do Tesouro Transparente (antes de 2017).

Figura 3 - Página interna do site do Tesouro Transparente antes de 2017

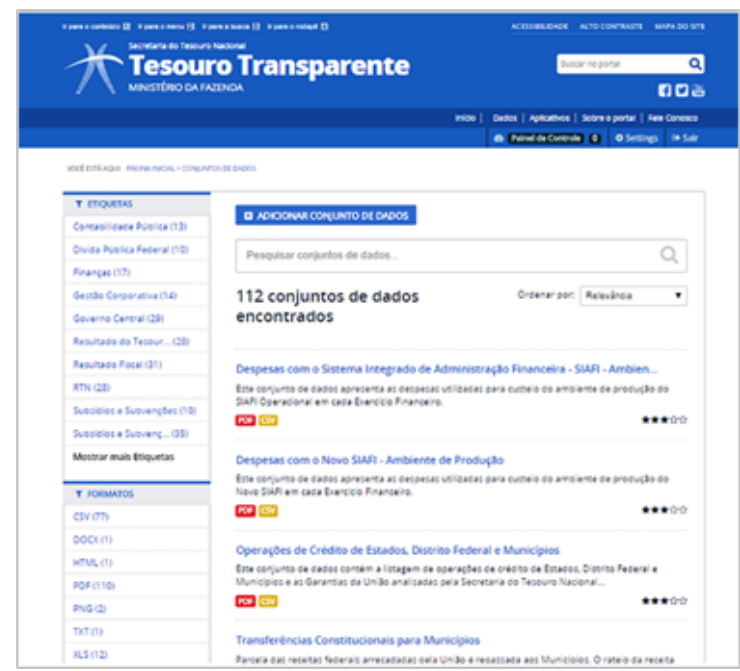

Fonte: Portal do Tesouro Transparente (antes de 2017). 
Figura 4 - Painel do Teto de Gastos do Governo Federal

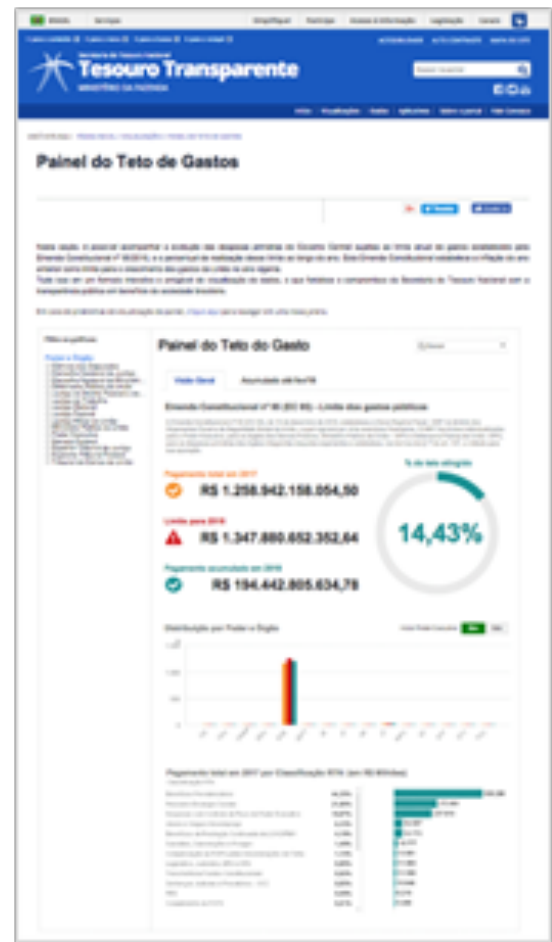

Fonte: Portal do Tesouro Transparente (após 2017).

(http://www.tesourotransparente.gov.br/visualizacoes/painel-do-teto-de-gastos)

Figura 5 - Painel da Regra de Ouro da União
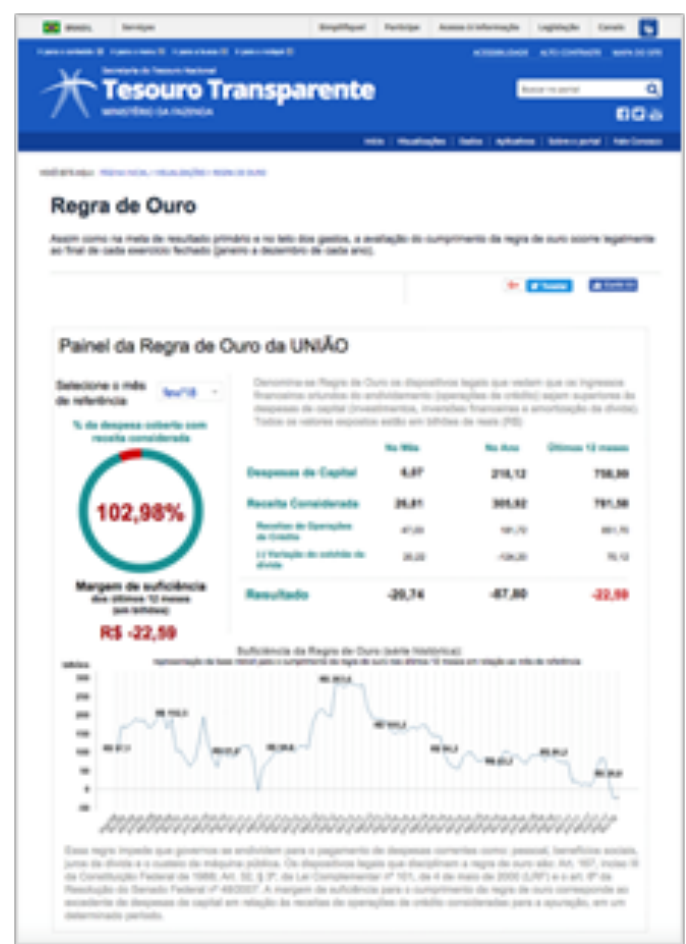

Fonte: Portal do Tesouro Transparente (após 2017).

(http://www.tesourotransparente.gov.br/visualizacoes/regra-de-ouro) 
Órgãos governamentais têm aumentado o número de profissionais da área de design, porém o conhecimento desses profissionais acaba por vezes sendo subutilizados. O conhecimento do design de informação e interação, quando bem aproveitado pelo governo, pode contribuir com uma comunicação visual mais efetiva e transparente, sendo esta uma das hipóteses a ser comprovada com esta pesquisa.

\section{Lei de acesso à informação}

O Governo Brasileiro, em 2011, criou a LAI ${ }^{4}$ - Lei de Acesso à Informação no 12.527/2011, que regulamenta o direito constitucional do acesso dos cidadãos às informações públicas. A disponibilização destes dados abertos não necessariamente caracteriza que a informação disponível esteja compreensível e acessível conceitualmente ao cidadão.

Para que uma informação chegue ao cidadão de forma clara, precisa e eficiente, o uso gráfico-visual interativo atualmente chamado de data visualization é um recurso muito rico para "tornar a prática de excelência gráfica, a eficiente comunicação de ideias complexas" (TUFTE, 2002, p.15).

\section{Visualização de Dados}

Atualmente empresas de softwares estão investindo no trabalho de tratamento de dados sob a forma de data visualization, com ferramentas como o Tableau e ClickView reconhecidos no mercado como referência pelo site da Forbes ${ }^{5}$, por exemplo. Estes softwares facilitam o cruzamento de dados na forma visual. 0 design de informação e interação tem, por exemplo, 0 papel de agregar melhores soluções visuais e conceituais possibilitadas por estas ferramentas.

O design editorial de impressos sempre buscou conhecer o público alvo do seu produto a fim de construir uma interface gráfica estática que melhor se adequasse ao seu usuário final. Com o avanço das tecnologias digitais de $B I$ (compreensão do comportamento do usuário na rede conhecida como Business Intelligence), o público desses conteúdos ou materiais de informação gráfico-visual online, leva à personalização de interface entre o homem e dispositivos tecnológicos. Desta forma, é cada vez maior a personalização de informações baseada no mapeamento de comportamento desse usuário na rede. O trabalho do designer da Informação e Interação é compreender o usuário e gerar melhores visualizações gráfico-visuais personalizadas.

Hoje, toda e qualquer movimentação de um usuário que navega na internet gera informações sobre o seu comportamento, deixando vestígios e criando um rastro online. Essa grande quantidade de informações chamada de big data, representa a coleta de dados online, transformando a informação em conhecimento. E esse conhecimento pode ser catalisado para a geração de informações gráfico-visuais de qualidade, de acordo com o perfil do usuário.

Ferramentas de visualização de dados geram informações disponíveis em tempo real, cada vez mais interessantes visualmente, agregando valor e interatividade à informação. Mas, será que essas informações visuais são compreensíveis ou são somente esteticamente agradáveis? Silva e Stabile citam o termo data porn como sendo esta pornografia informacional onde a sedução visual mascara a informação que muitas vezes não é compreensível. (SILVA. STABILE. 2016, p.284). Este é um ponto a ser considerado na criação de visualizações de dados.

\footnotetext{
${ }^{4}$ LAi - http://www.acessoainformacao.gov.br/assuntos/conheca-seu-direito/a-lei-de-acesso-a-informacao.

${ }^{5}$ Forbes online. The 7 Best Data Visualization Tools In 2017.
} 
A interação e atualização instantânea de informações permite uma sociedade mais participativa e crítica. E, para a sociedade ser crítica, ela precisa compreender a informação à qual está sendo submetida. Desta forma, o recurso de data visualization tem o objetivo de aproximar informações da sociedade de forma clara, simples e objetiva propiciando uma comunicação efetiva de sucesso.

Abaixo, podemos observar dois exemplos de painéis de visualização de dados do site do Tesouro Transparente. O painel da Prévia Fiscal e o Painel da Regra de Ouro da União. Estes são exemplos de painéis que unem a estética, interatividade e personalização de escolhas de dados que geram resultados gráfico-visuais.

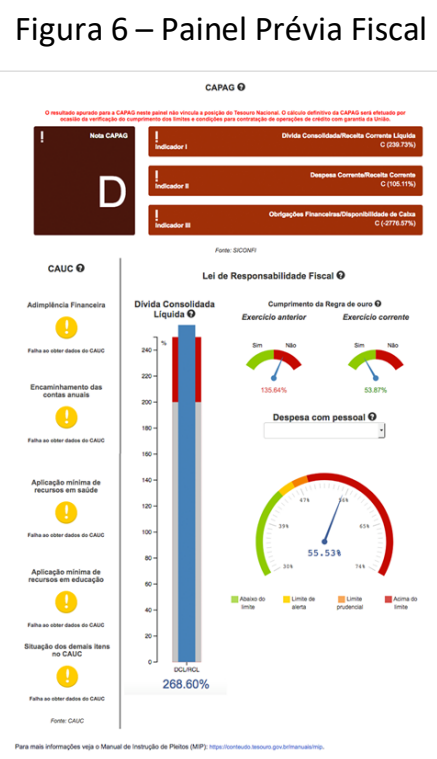

Fonte: Painel da Prévia Fiscal - Site Tesouro Transparente

(http://www.tesourotransparente.gov.br/visualizacoes/previa-fiscal, visitado em 19 de jun de 2018, às 23h)

Figura 7 - Painel da Regra de Ouro da União

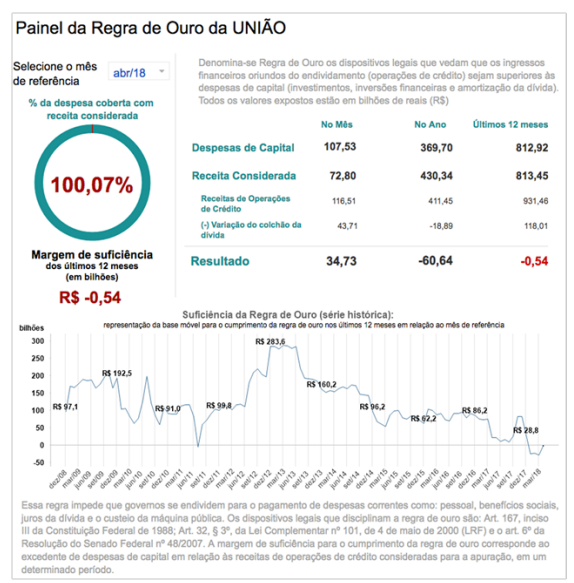

Fonte: Painel da Regra de Ouro da União - Site Tesouro Transparente (http://www.tesourotransparente.gov.br/visualizacoes/regra-de-ouro, visitado em 19 de jun de 2018, às 23h) 
As tecnologias digitais avançam rapidamente assim como se busca a melhor relação do homem com essas tecnologias. Tecnologias são extensões do homem e existem desde que ele criou, pegou e usou o primeiro martelo, a fim de facilitar a sua atividade. À medida que as tecnologias digitais e conectadas avançam em tudo que nos rodeia, a chamada internet das coisas (IOT - Internet of things) cria conexões e relações que necessitam de clareza para uma compreensão efetiva. A adaptabilidade humana de interagir com um dispositivo tecnológico que gera dados gráfico-visuais é um vasto campo de pesquisa para o designer de informação e interação.

As ferramentas geradoras de big data como $B I$ estão constantemente mapeando os usuários no mundo online. O designer de informação e interação pode fazer uso dessas informações para estudar as relações entre o homem e a interface tecnológica mais adequadamente, a fim de gerar uma melhor compreensão cognitiva de dados apresentados sob a forma gráfico-visual.

\section{Considerações finais}

O trabalho está em desenvolvimento no Programa de Pós-Graduação em Design da Universidade de Brasília (UnB), na linha de pesquisa de Design de Informação e Interação. A pesquisa encontra-se no momento de aprofundamento do conhecimento dos diversos dados de governo hospedados no portal do Tesouro Transparente, a fim de elencar um melhor estudo de caso a ser analisado.

Até o momento, buscou-se aprofundar e reconhecer as relações entre o homem e dispositivos tecnológicos que geram informações gráfico-visuais, com o objetivo de facilitar a compreensão da visualização e comunicação de dados de "forma clara, precisa e eficiente". (TUFTE, 2002, p.3). A pesquisa também busca aprofundar questões relacionadas à visualização de dados de governo em sites de outras instituições governamentais.

\section{Referências bibliográficas - Livros}

BONSIEPE, Gui. Design, Cultura e Sociedade. $2^{a}$ impressão. São Paulo: Blucher, 2013.

HORIE, Ricardo M.; PLUVINAGE, Jean. Revistas digitais para iPad e outros tablets - Artefinalização, geração e distribuição. São Paulo: Bytes \& Types, 2011.

LÉVY, Pierre. As tecnologias da Inteligência - O futuro do pensamento na era da informática. Tradução de Carlos Irineu da Costa. São Paulo: Editora 34. 1992.

LOGAN. Robert K. O que é Informação? A propagação da organização na biosfera, na simbolosfera, na tecnosfera e na econosfera. Rio de Janeiro: Contraponto. 2012.

McLUHAN, Marshall. Os Meios de Comunicação como Extensões do Homem. São. Paulo: Editora Cultrix. 1969.

PREECE, Jeninfer; ROGERS, Yvonne; SHARP, Helen. Design de Interação. Além da Interação homem-computador. Porto Alegre: Bookmam. 2008.

SANTAELLA. Lúcia. Culturas e artes do pós-humano. São Paulo: Editora Paulus . 2013.

SILVA, Tarcízio; STABILE, Max. Org. Monitoramento e Pesquisa em Mídias Sociais. Metodologias, aplicações e inovações. IBPAD. Instituto Brasileiro de Pesquisa e Analise de Dados. São Paulo: Ed. 
Uva Limão. 2016.

STIFELMAN KATZ, Fabiana. Estudo de comportamento de consumo de livros digitais. Porto Alegre: 2011. Disponível em

http://www.lume.ufrgs.br/bitstream/handle/10183/33251/000786952.pdf?sequence=1. Acesso em 30 dez 2016.

TUFTE, E. R. Envisioning Information. Connecticut: Graphics Press. Cheshire. 1998.

TUFTE, E. R. The Visual of Quantitative Information. (Mini Tuftte). 2002.

VISOCKY O'GRADY, J. \& K. The Information Design Handbook. Ohio. Estados Unidos: How Books. 2008.

VASSÃO. Caio Adorno. Metadesign. Ferramentas, estratégias e ética para a complexidade. São Paulo: Blucher. 2010.

\section{Referências bibliográficas - Web sites}

Brasileiros com Internet no Smartphone chegam a 76 Milhões. Disponível em:

http://www.nielsen.com/br/pt/press-room/2015/Brasileiros-com-internet-no-smartphonechegam-a-76-milhoes.html. Acesso em 20 nov. 2016.

DTBR - Design Thinking Brasil. Disponível em http://www.dtbrbook.com.br/\#. Acesso em 28 nov 2016.

How the Mobile Consumer Connects Around the Globe. Disponível em:

http://www.nielsen.com/in/en/insights/news/2013/how-the-mobile-consumer-connects-aroundthe-globe.html. Acesso em 28 abr 2013.

Tesouro Nacional. Tesouro lança nova versão do Portal Tesouro Transparente. Disponível em: http://www.tesouro.fazenda.gov.br/-/tesouro-lanca-nova-versao-do-portal-tesouro-transparente. Acessado em 4 abr 2018.

Tesouro Transparente. Painel do Teto de Gastos do Governo Federal. Disponível em: http://www.tesourotransparente.gov.br/visualizacoes/painel-do-teto-de-gastos. Acessado em 8 nov 2017.

Tesouro Transparente. Painel da Regra de Ouro. Disponível em: http://www.tesourotransparente.gov.br/visualizacoes/regra-de-ouro. Acessado em 5 nov 2018.

Smartphone é o dispositivo mais usado para acessar a internet. The Nilesen Company. Mobile Report, Nielsen IBOBE. Disponível em:

http://www.nielsen.com/br/pt/insights/news/2015/Smartphone-e-o-dispositivo-mais-usado-paraacessar-a-internet.html. Acesso em 28 abr 2015.

Forbes online. The 7 Best Data Visualization Tools In 2017. Disponível em: https://www.forbes.com/sites/bernardmarr/2017/07/20/the-7-best-data-visualization-tools-in2017/\#5db90d086c30. Acesso em 5 abr 2018. 